\title{
Man Versus Machine: What's the Standard?
}

At 2:45 pm on Thursday, May 6, 2010, the Dow Jones Industrial Average was already down $3.9 \%$ on fears that the Greek economy was in free-fall. Suddenly, in 5 minutes, the index plunged 573 points. Less than 2 minutes later, the Dow had rocketed back up 543 points, going on to finish the day down $3.2 \%$. The "flash crash," as it was described, was attributed to computerized trading on the part of several high-frequency trading firms. The machines that were making so much money for their corporate masters nearly caused a second market downturn during a time of tenuous market recovery. ${ }^{1}$

The concept of a computer-driven trading environment is a reality Wall Street investors deal with daily. Is this the future of medical care as well? Following the Institute of Medicine's report "To Err is Human: Building a Safer Health System," ${ }^{2}$ the specialty of critical care medicine hastily began to institute protocols and care bundles into routine clinical practice, with the belief that through standardization and simplification of tasks based on best-practice guidelines, caregivers would be more likely to deliver error-free care to the critically ill. ${ }^{3}$ Providers are now witnessing the natural progression of this type of standardized care as medical knowledge is integrated into computerdriven protocols. Such care protocols are being incorporated into the medical devices we use daily in the intensive care unit and are becoming part of the reality of critical care practiced in 2011.

See the Original Study on Page 271

In this issue of ResPiratory CARE, Bonnett and colleagues 4 "reintroduce" readers to a computerized system meant to aid in the provision of care to patients requiring mechanical ventilation. They described an open-loop advisory system that continuously provides caregivers recommendations relevant to the titration of pressure support ventilation (PSV). Bonnett et al utilize a unique load and tolerance strategy embedded in a sophisticated fuzzy logic inference system incorporating a well developed and tested artificial neural network. Recommendations made by the advisory system are validated against a group of critical care Registered Respiratory Therapists (RRTs). In the conclusion of the paper, Bonnett et al remind us that the logical progression of their work would allow ventilatorassisted breaths delivered during PSV to be controlled by a computer-driven algorithm. They specifically comment that in clinical situations where intensive care unit staff are limited and unable to perform bedside assessment, this system would be at its most useful. It is hard not to embrace this thought, given that approximately $40 \%$ of the total duration of mechanical ventilation is focused upon the weaning process and that non-protocolized care directed by physicians often leads not to safer more individualized care but, rather, error-prone and inefficient care. .,5, $^{3}$ Given this recurring finding, why not try to remove ventilator management from the hands of man? All would agree that inappropriate management of mechanical ventilation can and will lead to multiple complications and that liberation from mechanical ventilation should occur as rapidly as possible. ${ }^{7,8}$

Unfortunately, the application of computer-driven protocolized weaning has not met the stirring successes of manually applied weaning protocols or guidelines, which have been shown to reduce the duration of weaning and mechanical ventilation. ${ }^{9,10}$ Perhaps, as Bonnett et al imply, the protocols driving the mechanized weaning process are somehow flawed; perhaps in their current versions they are not "one size fits all"? Two studies, both using the SmartCare system (Dräger Medical, Lübeck, Germany), found contradictory results. Lellouche and colleagues ${ }^{11}$ were successful in demonstrating accelerated computerdriven weaning, when compared to a physician-controlled process. In direct opposition to that finding, Rose and colleagues $^{12}$ found approximately $30 \%$ prolongation of the time patients required to reach "separation potential." Speculation as to why such widely varied findings occurred includes intensity of staffing in the units under study, the duration of ventilation prior to weaning, and the severity of illness of the population studied. Taniguchi and colleagues ${ }^{13}$ found PSV weaning similar to manual weaning in a study published last year, utilizing a weaning paradigm designed by a different ventilator manufacturer. Unfortunately, the "auto-wean" patients had significantly more complications during the study period. In all 3 studies, the computer-driven paradigms used measured end points reflecting patients' tolerance of the defined level of support. Could this be the issue? Clearly the failure to insufficiently reduce inspiratory load during weaning has been demonstrated to be a factor preventing successful outcomes. ${ }^{14}$ Could the integration of load assessment into the automated controller's algorithm be the necessary step to move 
critical care providers that much closer to an automated weaning system? It will be interesting to observe how this novel two-side approach to automated weaning fares in future clinical trials and whether it can be successfully applied across various patient populations.

Another issue raised by this paper ${ }^{4}$ is the "reintroduction" of the PSV advisory system. As carefully and appropriately described in the paper's introduction, this study is actually a replica of a previous investigation performed by the same group and published 2 years earlier in Chest. ${ }^{15}$ In the current study, new patients were enrolled, but the only important differences between the earlier paper and the current version are the validation group (critical care physician vs critical care RRTs) and the study site (multiinstitution vs single). A pragmatic question thus arises: is it reasonable to expect different results from experienced critical care physicians and experienced critical care RRTs with respect to the outcome of relevance: adjustment of the pressure support level? Clearly, the use of RRTs as the validation group makes this paper attractive to RESPIRATORY CARE. However, it is not clear to me what new information is revealed by presenting the advisory system again in a smaller single-site study with only this relevant change in design.

For this study to be worthy of publication, one would have to opine that it adds new information to the body of medical knowledge-that there are important differences in knowledge and management style between physicians and respiratory therapists addressing ventilator-patient synchrony during PSV. These 2 studies actually reinforce this doubt, as both papers describe the same "traditional" approach of assessing spontaneous breathing pattern data, regardless of whether the validation group is physician or therapist. Does it seem logical to expect different results? The assessments of spontaneous breathing pattern data, utilizing the frequency range $15-25$ breaths/min and tidal volume range $6-8 \mathrm{~mL} / \mathrm{kg}$ ideal body weight, as well as absence of sternocleidomastoid muscle contraction and the subjective appearance of comfortable breathing, are identical. Do therapists and physicians somehow view such objective data differently? The answer can only be no. It is no surprise that in both papers the practitioners agreed with the advisory system at an almost identical rate (physicians $90.5 \%$ and RRTs $91 \%$ ).

Given these data, one might again question publication of this paper. Bonnett and colleagues attempt to respond to this potential criticism by stating that in some situations experienced critical care RRTs may be tasked to guide ventilator management once a management algorithm is agreed upon between RRT leadership and the intensive care unit attending medical staff. ${ }^{4}$ However, since RRTs are expected to posses the same body of knowledge as physicians when it comes to setting the ventilator, that reason simply does not suffice. ${ }^{8,16}$ An alternative view supporting publication of both papers might advocate the current study as an affirmation that the assessment skills of experienced physicians and experienced RRTs are identical. If this is indeed the case, these papers support the notion that therapist-driven weaning protocols are successful not due to greater knowledge or more experience, but, rather, the amount of time one focuses on the task. Supporting this view is the computer-driven weaning study by Rose and colleagues, where neither physicians nor RRTs directed weaning, but, rather, critical care nurses, at a rate far better than the computer. ${ }^{12}$

In the end, the load and tolerance paradigm of defining appropriate PSV settings presented by Bonnett and colleagues may be the next advance forward in automatic weaning. Future studies will not only need to investigate whether this novel paradigm can improve upon current commercially available products, but whether this more robust paradigm can show benefit in a variety of patients and settings, when compared to a range of critical care providers (physicians, RRTs, and nurses). If nothing else, this study reinforces the point that the provision of respiratory care is not the responsibility of any single man or any single machine.

$$
\begin{array}{r}
\text { Steven J Lisco MD } \\
\text { Department of Anesthesiology } \\
\text { University of Cincinnati College of Medicine } \\
\text { Cincinnati, Ohio }
\end{array}
$$

\section{REFERENCES}

1. Peltz, M. Man vs machine: inside the world of high frequency trading, September 2010; http://www.cnbc.com/id/39099331. Accessed December 29, 2010.

2. Kohn LT, Corrigan JM, Donaldson MS. To err is human: building a safer health system. Washington: Institute of Medicine, National Academy Press; 2000.

3. Bion JF, Abrusci T, Hibbert P. Human factors in the management of the critically ill patient. Br J Anaesth 2010;105(1):26-33.

4. Bonnett S, Banner MJ, Euliano NR, Peters CW, Layon AJ, Gabrielli A. Pressure support ventilation advisory system provides valid recommendations for setting ventilator. Respir Care 2011;56(3):271277.

5. Esteban A, Alia I, Ibanez J, Benito S, Tobin MJ; the Spanish Lung Failure Collaborative Group. Modes of mechanical ventilation and weaning: a national survey of Spanish hospitals. Chest 1994;106(4): 1188-1193.

6. Kollef MH, Micek ST. Using protocols to improve patient outcomes in the intensive care unit: focus on mechanical ventilation and sepsis. Semin Respir Crit Care Med 2010;31(1):19-30.

7. Tobin MJ. Advances in mechanical ventilation. N Engl J Med 2001; 344(26):1986-1996.

8. MacIntyre NR, Cook DJ, Ely EW Jr, Epstein SK, Fink JB, Heffner $\mathrm{JE}$, et al. Evidence-based guidelines for weaning and discontinuing ventilatory support: a collective task force facilitated by the American College of Chest Physicians; the American Association for Respir Care; and the American College of Crit Care Med. Chest 2001; 120(6 Suppl):375S-95S. 


\section{Man Versus Machine: What's the Standard?}

9. Ely EW, Baker AM, Dunagan DP, Burke HL, Smith AC, Kelly PT, et al. Effect on the duration of mechanical ventilation of identifying patients capable of breathing spontaneously. N Engl J Med 1996; 335(25):1864-1869.

10. Ely EW, Bennett PA, Bowton DL, Murphy SM, Florance AM, Haponik EF. Large scale implementation of a respiratory therapistdriven protocol for ventilator weaning. Am J Respir Crit Care Med 1999;159(2):439-446.

11. Lellouche F, Mancebo J, Jolliet P, Roeseler J, Schortgen F, Dojat M, et al. A multicenter randomized trial of computer-driven protocol-

The author has disclosed no conflicts of interest.

Correspondence: Steven J Lisco MD, Department of Anesthesiology, University of Cincinnati College of Medicine, 231 Albert Sabin Way, Mail Location 670531, Cincinnati OH 45267. E-mail: steven. lisco@uc.edu.

DOI: $10.4187 /$ respcare.01257 ized weaning from mechanical ventilation. Am J Respir Crit Care Med 2006;174(8):894-900

12. Rose L, Presneill JJ, Johnston L, Cade JF. A randomised, controlled trial of conventional versus automated weaning from mechanical ventilation using SmartCare/PS. Intensive Care Med 2008;34(10): 1788-1795.

13. Taniguchi C, Eid RC, Saghabi C, Souza R, Silva E, Knobel E, et al. Automatic versus manual pressure support reduction in the weaning of post-operative patients: a randomised controlled trial. Crit Care 2009;13(1):R6.

14. Vassilakopoulos T, Zakynthinos S, Roussos C. The tension-time index and the frequency/tidal volume ratio are the major pathophysiologic determinants of weaning failure and success. Am J Respir Crit Care Med 1998;158(2):378-385.

15. Banner MJ, Euliano NR, Macintyre NR, Layon AJ, Bonett S, Gentile MA, et al. Ventilator advisory system employing load and tolerance strategy recommends appropriate pressure support ventilation settings: multisite validation study. Chest 2008;133(3): 697-703.

16. Barnes TA, Gale DD, Kacmarek RM, Kageler WV. Competencies needed by graduate respiratory therapists in 2015 and beyond. Respir Care 2010;55(5):601-616 